\author{
Beata Kunat \\ Wydzią Pedagogiki i PsychologiI \\ UNIWERSYTET W BIAŁYMSTOKU \\ E-MAIL: B.KUNAT@UWB.EDU.PL
}

\title{
POMIĘDZY SZTUKĄ A BADANIEM NAUKOWYM. ETNOGRAFIA WIZUALNA JAKO ŹRÓDŁO WIEDZY O RZECZYWISTOŚCI EDUKACYJNEJ
}

\section{Wprowadzenie}

Celem artykułu jest, po pierwsze, ukazanie różnych obszarów relacji sztuki i nauki z perspektywy epistemologicznych i ontologicznych poszukiwań filozofów nauki [Whitehead 1998; Popper 2002] oraz badaczy sztuki współczesnej [Kluszczyński 2011; Broeckmann 2015; Kisseleva 2015; Reichle 2015]. Po drugie - pokazanie istoty interakcji sztuki z pedagogiką, której złożony przedmiot badań sprawia, że otwiera się ona na różne źródła, style, języki poznania i rozumienia świata i człowieka (między innymi język nauki i sztuki). Po trzecie - zwrócenie uwagi na sztukę jako ważne narzędzie analizy edukacji w jakościowych badaniach pedagogicznych usytuowanych $\mathrm{w}$ paradygmacie interpretatywnym. W artykule postawiono tezę, że etnografia wizualna oscylująca pomiędzy sztuką a nauką jest cennym źródłem wiedzy o rzeczywistości edukacyjnej. W związku z tym kluczowym zamierzeniem autora tekstu jest zaprezentowanie założeń etnografii wizualnej jako naukowej metody badawczej, odwołującej się do obrazu jako podstawowego medium sztuki. W konsekwencji w artykule dokonano analizy pedagogicznych projektów badawczych odwołujących się do danych wizualnych, realizowanych na gruncie polskim. Na zakończenie wskazano korzyści poznawcze i praktyczne wynikające $\mathrm{z}$ odwoływania się w pedagogicznych projektach badawczych do wiedzy oraz kategorii językowych wywodzących się z kręgu sztuki jako źródła wiedzy o rzeczywistości edukacyjnej. 
W poszukiwaniu obszarów relacji „sztuki” i „nauki”

Podstawowe dla artykułu pojęcia „sztuka” i "nauka” są wieloznaczne i wielozakresowe. W publikacjach naukowych można odnaleźć wiele ujęć definicyjnych tych kategorii. Poszukując znaczeń terminu „sztuka” warto odwołać się do jej alternatywnej definicji sformułowanej przez Władysława Tatarkiewicza, zgodnie z którą sztuka ,jest odtwarzaniem rzeczy, bądź konstruowaniem form, bądź wyrażaniem przeżyć - jeśli wytwór tego odtwarzania, konstruowania, wyrażania jest zdolny zachwycać, bądź wzruszać, bądź wstrząsać” [Tatarkiewicz 1982: 52]. Pojęcie „nauki” odnieść można natomiast do działalności umysłowej lub umysłowo-fizycznej oraz do poznania jako podstawowej i pierwotnej aktywności psychicznej [Kamiński 1992: 13]. Zarówno kategoria sztuki, jak i nauki przez autorkę tekstu są traktowane jako formy ludzkiego poznania i doświadczania świata.

W filozoficznych rozważaniach dotyczących epistemologicznych i ontologicznych podstaw nauki odnaleźć można nurt poszukiwań powiązań między sztuką i nauką [Whitehead 1998; Popper 2002]. Filozof nauki Alfred N. Whitehead podkreśla, że nauka ze sztuką pozostaje w bliskiej łączności, jednak bardziej w sensie podobieństwa niż współzależności [Whitehead 1998: 206-207]. Zgodnie z jego ujęciem, twórczość naukowa i artystyczna mają cechy wspólne: sztuka wchodzi na teren prawdy, widoczny jest także związek nauki i sztuki w aspekcie konstrukcyjno-twórczym [Whitehead 1998]. Liczne podobieństwa sztuki z nauką dostrzega także Karl R. Popper [2002].

$\mathrm{Na}$ różne obszary współdziałania czynników naukowych i artystycznych wskazują także badacze sztuki [Kluszczyński 2011; Broeckmann 2015; Kisseleva 2015; Reichle 2015]. Ryszard W. Kluszczyński, analizując charakter relacji występujących pomiędzy sztuką a nauką oraz wynikające z nich konsekwencje, wyodrębnia trzy typy takich związków. Określa je przy użyciu formuł: „nauka dla sztuki”, „sztuka dla rzeczywistości (kształtowanej przez naukę)”, „sztuka dla nauki” [Kluszczyński 2011]. Zgodnie z koncepcją przywoływanego autora typ związku „nauka dla sztuki” jest najbardziej popularny w świecie współczesnych praktyk artystycznych. W jego ramach pojawiają się różnorodne formy obrazowości o charakterze i źródle naukowym (zdjęcia astronomiczne, mikroskopowe, rentgenowskie), dźwięki osiągalne wyłącznie dzięki zastosowaniu narzędzi badawczych, struktury czerpiące kształty ze sfery prac naukowych. W efekcie takich zabiegów są 
tworzone dzieła odwołujące się do nowego rodzaju estetyki, wymagające od odbiorców bardziej złożonych kompetencji oraz innego typu wrażliwości.

W typie związków „sztuka dla rzeczywistości (kształtowanej przez naukę)” sztuka spełnia funkcję adaptacyjną, wprowadza odbiorców w rzeczywistość, której wyznaczniki są kształtowane przez naukę. Obrazy, formy czy struktury wydarzeniowe są wytworami procedur naukowych oraz powołują do życia środowiska, których doświadczenie przekracza swym odniesieniem ramy estetyki, stając się formą poznania nowego ładu istnienia. W relacji „sztuka dla nauki” sztuka działa na rzecz nauki dzięki produkowaniu wiedzy, tworzeniu nowych kontekstów i inspiracji. Artyści angażują się w wielowymiarowe przedsięwzięcia, ich działania przekraczają i znoszą granice oddzielające sztukę od innych działań społecznych [Kluszczyński 2011: 32-42].

\section{Sztuka a pedagogika jako nauka badająca rzeczywistość edukacyjną}

W artykule przyjmuje się, że egzemplifikacją nawiązania relacji nauki ze sztuką jest pedagogika. Złożony przedmiot badań pedagogiki jako nauki opisującej i wyjaśniającej różne formy i konteksty praktyki edukacyjnej [Rubacha 2004: 21] sprawia, że posługuje się ona wieloma językami (m.in. językiem sztuki), badając złożoną rzeczywistość edukacyjną. Badacze pedagogiki wskazują na potrzebę poszerzania kompetencji multijęzycznych w procesie poznawania wielowymiarowej rzeczywistości edukacyjnej [m.in. Rutkowiak 1994, Hejnicka-Bezwińska 2008]. Jak zaznacza Teresa Hejnicka-Bezwińska [2008: 269], aby rozpoznać współczesny obraz rzeczywistości edukacyjnej niezbędne jest odwołanie się do wielu stylów myślenia oraz różnych języków jej opisywania. Zgodnie z ujęciem Joanny Rutkowiak [1994], obok naukowego, potocznego, filozoficznego oraz religijnego stylu językowego kreowania rzeczywistości edukacyjnej, ważnym źródłem wiedzy o wychowaniu człowieka jest język z kręgu sztuki.

Sztuka stała się dziś ważnym narzędziem poszukiwań jakościowych badań pedagogicznych usytuowanych $\mathrm{w}$ paradygmacie interpretatywnym, który jest zakorzeniony w subiektywistycznej wizji natury społecznej i teorii poznania. Perspektywa ta jest zorientowana na zrozumienie rzeczywistości w takiej postaci, w jakiej jawi się ona jej uczestnikom. Poprzez odwołanie się do świadomości, doświadczeń, przekonań, wyobrażeń ludzi, którzy stale konstruują i rekonstruują swoje działania [Sławecki 2012: 78]. Prowadzone w nurcie interpretatywnym badania jakościowe nie są nasta- 
wione na dane obiektywne, mierzalne, lecz na procesy i znaczenia, jakie ludzie nadają zdarzeniom $\mathrm{w}$ procesie ich doświadczania i przeżywania.

W badaniach jakościowych zauważa się wyraźny rozwój nurtu badań poprzez sztukę [m.in. Barone 2001; Huss, Cwikel 2005; Finley 2005; Cole, Knowles 2007; Taylor, Wilder, Helms 2007], których idea opiera się na synergii poznania naukowego i artystycznego w ramach wszystkich etapów postępowania badawczego nastawionego na pogłębione rozumienie idiomatycznych zjawisk humanistycznych i społecznych. Metoda ta polega na wykorzystaniu poznawczego potencjału różnych dziedzin sztuki i przejawów aktywności artystycznej w diagnozowaniu, rozumieniu i interpretowaniu aktualnych problemów społecznych. Zakłada się, że sztuka i aktywność artystyczna mogą dostarczyć cennej wiedzy humanistyczno-społecznej i w związku z tym aranżuje się twórczość między innymi plastyczną, literacką, teatralną, muzyczną, taneczną, fotograficzną, multimedialną badanych podmiotów w celu partycypacyjnego interpretowania ich rezultatów w kontekście problematyki badawczej [Kubinowski 2013: 207]. Badania poprzez sztukę obejmują podejścia mające na celu poszerzenie tradycyjnych możliwości naukowego uchwycenia i wyrażania kompleksowości ludzkiego doświadczenia w jego różnorodności. Metodologia ta stara się integrować języki, przekazy, formy sztuk literackich, wizualnych, widowiskowych, muzycznych i odwoływać się do ich wrażliwości, logiki i idiomów w procesie badawczym [Kubinowski 2011: 189]. W podejściu tym nakładają się na siebie role badacza, artysty i animatora działań artystycznych badanych. Relacje między badaczem a uczestnikiem badań są intensywne, bazujące na emocjach. Sztuka staje się jednocześnie metodą badań - sposobem i środkiem rozumienia drugiego człowieka oraz instrumentem działań - wzmocnieniem, wzbogaceniem oraz medium autoekspresji [Kubinowski 2011: 190].

\section{Etnografia wizualna jako przykład „czerpania wiedzy” z języka sztuki (obrazu)}

Ważnym źródłem wiedzy o rzeczywistości społecznej i edukacyjnej pedagogicznych badań jakościowych są przedstawienia wizualne: obrazy, fotografie, filmy, stanowiące kwintesencję języka sztuk wizualnych. Przykładem badawczego eksplorowania tego swoistego języka w celu poznawania różnych przejawów kultury i codzienności człowieka jest etnografia wizualna. Jest ona traktowana przez badaczy jako metodologia scalająca różne 
procedury pozyskiwania, analizowania i interpretowania danych wizualnych [Banks 2009; Pink 2008; Rose 2010]. Jak twierdzi Sarah Pink [2008: 34], etnografia wizualna jest sposobem doświadczania, interpretowania, przedstawiania kultury czy społeczności, który przenika zbiór procedur badawczych. Jest ona metodą zbierania danych, ale także procesem tworzenia i przedstawiania wiedzy opartym na własnych doświadczeniach etnografa. Założenia teoretyczne i metodologiczne etnografii wizualnej odnoszą się do badawczych tradycji antropologii obrazu [zob. m.in. Worth 1981; Collier i Collier 2009; Olechnicki 2003a, 2003b; Sikora 2003; Belting 2007; Banks, Ruby 2011], socjologii wizualnej [zob. m.in. Becker 1995; Koseła 1990; Ferenc 2001; Konecki 2005b; Sztompka 2005; Schnettler 2008; Frąckowiak; Rogowski 2009; Drozdowski, Krajewski 2010] oraz historii sztuki [zob. m.in. Ripa 2010; Mitchell 1994, 2009].

Na gruncie polskiej pedagogiki całościowe podejście do etnografii wizualnej zarówno w kontekście teorii, jak i praktyki badawczej odnaleźć można w publikacji Justyny Nowotniak Etnografia wizualna $w$ badaniach i praktyce pedagogicznej [2012]. Zgodnie z ujęciem tej autorki, etnografia wizualna służy potrzebie badania kultury wizualnej szkoły rozumianej jako splot procesów komunikacji wizualnej oraz wszechstronnych interakcji, jakie stają się udziałem członków danej społeczności wtedy, gdy wytwarzają oni artefekty wizualne. Kultura wizualna jest konstrukcją społeczną, a badania wizualne jej odkrywaniem poprzez wykorzystanie jej reprezentacji wizualnych [Nowotniak 2012: 64].

Zastosowanie etnografii wizualnej $\mathrm{w}$ badaniach pedagogicznych ma na celu pogłębienie rozumienia człowieka poprzez dopełnienie źródeł mówionych i pisanych, przekazów werbalnych i reprezentacji opisowych wszelkiego rodzaju danymi odbieranymi i analizowanymi wzrokowo [Kubinowski 2013: 183]. Dane wizualne mogą być traktowane jako prawomocne i wartościowe materiały empiryczne, na podstawie których można budować pewne teorie i propozycje teoretyczne. Mogą być rozpatrywane w zestawieniu $\mathrm{z}$ innymi, jako pewien uzupełniający typ danych, bądź też wykorzystane jako dane podstawowe projektów badawczych [Nowotniak 2013: 17].

\section{Pedagogiczne projekty badawcze odwołujące się do danych wizualnych}

Badania wizualne, rozwijane w szerokim zakresie na gruncie socjologii [m.in. Ferenc 2001, 2005; Konecki 2005a, 2005b, 2008, 2010, 2012; Magala 1978, 2012; Niziołek 2010, 2011, 2012; Olechnicki 2003a, 2003b; Piejko 2008; 
Sikora 2004; Sztompka 2005; Worth 1981; Levin 1993; Anker i Nelkin 2003; Dikovitskaya 2005], realizowane są współcześnie także przez pedagogów. W polskiej pedagogicznej praktyce badawczej zauważa się obecnie widoczny zwrot w kierunku stosowania elementów etnografii wizualnej [Bylica, Dąbrowski 2009; Krzychała, Zamorska 2008; Mendel 2006, 2009; Nalaskowski 2002; Nowotniak 2001a, 2001b, 2012, 2013; Pryszmont-Ciesielska 2011; Siarkiewicz 2007; Sztejnberg 2006]. Przedstawienia wizualne (m.in. fotografie, filmy, nagrania wideo, prace plastyczne) wykorzystywane są do badania różnych aspektów edukacyjnego funkcjonowania człowieka.

Elementy metodologii etnografii wizualnej stosowane są między innymi w celu rozpoznania symboliki edukacyjnej w sposobie organizowania przestrzeni w instytucjach edukacyjnych. Przykładem tego typu analiz jest projekt badawczy Aleksandra Nalaskowskiego Przestrzeń i miejsca szkoły [2002]. Badacz połączył interpretację materiału wizualnego z badaniami ankietowymi. Jako źródło wiedzy o przestrzeni szkoły potraktował rysunki gimnazjalistów na temat szkoły ich marzeń, wizualizacje graficzne szkoły $\mathrm{w}$ różnych przestrzeniach symbolicznych, plany architektoniczne budynków szkoły, ilustracje historyczne, grafiki publikowane, obrazy, stare fotografie szkoły. Na podstawie zgromadzonych danych empirycznych autor dokonał typologii miejsc i przestrzeni szkolnych (szkoła jako miejsce spotkań, świątynia, rodzina, fabryka, plac gry, teatr, koszmar), jej przestrzeni w cyklu dnia i roku szkolnego (miejsca publiczne i intymne, „dzielnice” budynku szkolnego) oraz ważnych momentów z życia i kultury szkoły. Egzemplifikacją wizualnej analizy elementów organizacji przestrzeni środowiska uczenia się i nauczania w kontekście jej wpływu na komunikację społeczną jest natomiast projekt Aleksandra Sztejnberga i Tadeusza Jasińskiego Proksemika w komunikacji społecznej [2007]. W innym przedsięwzięciu badawczym Sztejnberg [2006], dzięki odwołaniu do materiałów wizualnych, ukazał wpływ wybranych sposobów przestrzennego usadowienia uczniów na komunikowanie się w klasie.

Kolejny nurt badań wykorzystujących dane wizualne w połączeniu z innymi metodami dotyczy badania codzienności szkolnej. Przykładem odnoszenia się do obrazów jako materiałów empirycznych przy zastosowaniu metody dokumentarnej jest projekt badania codzienności szkolnej Sławomira Krzychały i Beaty Zamorskiej [2008]. Przedsięwzięciem badawczym łączącym różne metody badawcze $\mathrm{z}$ analizą danych wizualnych jest też projekt Urszuli Bylicy i Bartosza Dąbrowskiego [2009], mający na celu poznanie wychowawczego znaczenia kabaretów młodzieżowych, ze szcze- 
gólnym uwzględnieniem ich roli w zakresie kształtowania krytycznego myślenia uczniów. Podstawę badań stanowiły zogniskowane wywiady grupowe z młodzieżą zajmującą się działalnością kabaretową. Analizie poddano również sfilmowaną przez badaczy twórczość kabaretową uczniów. Inną propozycją łączenia różnych metod badawczych (obserwacja) $\mathrm{z}$ analizą danych wizualnych zarejestrowanych za pomocą kamery wideo są badania Ireneusza Kaweckiego [1993, 1994, 2009] dotyczące stosowanych przez nauczycieli sposobów sprzyjających skuteczności uczenia.

Obok badania instytucji szkoły, dane wizualne wykorzystywane są także do analizy innych przestrzeni edukacyjnych [Mendel 2006, 2009]. Eksplorowane są również $\mathrm{w}$ pedagogicznych projektach badawczych $\mathrm{w}$ kontekście analiz z zakresu poradnictwa [Siarkiewicz 2007] oraz gerontologii edukacyjnej [Pryszmont-Ciesielska 2011].

Szereg pedagogicznych projektów badawczych skoncentrowanych na analizie danych wizualnych zrealizowała Justyna Nowotniak [2001a, 2001b, 2012], między innymi projekty dotyczące przestrzeni szkoły i jej ukrytych programów, odnoszące się do koncepcji kultury szkoły. Badaczka koordynowała także projekty badawczo-dydaktyczne w ramach prowadzonego przedmiotu Metodologia badań społecznych. Jeden z nich został poświęcony ubóstwu dzieci w dużym mieście. Studenci pedagogiki prowadzili badania na terenie szczecińskich zaniedbanych posesji (wywiady swobodne, kierowane, wywiady $\mathrm{z}$ interpretacją fotograficzną, obserwacje, analiza fotografii). Dzięki analizie materiału badawczego ukazano różne oblicza ubóstwa dzieci w wielkim mieście [Nowtotniak 2012]. Inny projekt dydaktyczny dotyczył sposobów spędzania przerw przez uczniów szczecińskich szkół podstawowych, gimnazjów i liceów. Do pozyskiwania danych użyto kilku technik badawczych: wywiadów swobodnych kierowanych, wywiadów $z$ interpretacją fotografii, fotografii wykonanych przez uczniów i studentów na temat „Jak spędzam przerwy w mojej szkole?” oraz obserwacji przerw śródlekcyjnych. Dzięki zastosowaniu metodologii etnografii wizualnej poszukiwano odpowiedzi na pytanie, w jaki sposób uczniowie spędzają przerwę, jakie formy aktywności podejmują w trakcie jej trwania i jak swoje wysiłki wizualizują [Nowotniak 2013].

Przykładem włączenia elementów pozyskiwania, analizy, interpretacji i raportowania danych wizualnych do procesu dydaktycznego są także zespołowe projekty badawcze dotyczące codzienności studentów pedagogiki realizowane w latach 2013-2015 na Wydziale Pedagogiki i Psychologii 
Uniwersytetu w Białymstoku pod kierunkiem Alicji Korzenieckiej-Bondar i Beaty Kunat w ramach przedmiotu Metody badań jakościowych.

\section{„Uchwycenie tego, co jest widoczne lecz niedostrzegane”, czyli możli- wości zastosowania etnografii wizualnej w badaniach edukacyjnych}

Justyna Nowotniak [2012: 260-263], na podstawie wieloletniego doświadczenia badawczego w zakresie stosowania etnografii wizualnej, wskazuje na jej potencjalne i rzeczywiste możliwości rozpoznawania rzeczywistości edukacyjnej w badaniach naukowych i praktyce edukacyjnej. Podkreśla, że wysoka mobilność danych wizualnych tworzy nową przestrzeń interakcji i uczestnictwa badanego. Obrazy służą poznawaniu rzeczywistości, którą jednocześnie konstruują przez reprezentacje wizualne. Znaczące obrazy mają moc budowania porządku społecznego, jako reprezentacji systemów klasyfikacyjnych i środków legitymizacji porządku społecznego. Obrazy mogą łączyć ludzi, tworząc więzi społeczne, gdyż wykonywanie i oglądanie zdjęć to działania więziotwórcze. Dane wizualne unaoczniają zjawisko odchodzenia od rozumienia bytu ludzkiego w kategoriach jedynie substancjonalnych i zastępują je kategorią bytu czasowego, służą uchwyceniu różnorodności sposobów artykułowania społecznych układów czasoprzestrzennych. Badania wizualne stanowią szansę na wykorzystanie bogatego spektrum pojęciowego nauk społecznych w różnorodnych kontekstach rozważań o edukacji. Dzięki nim można poznać kategorie niedostatecznie zbadane w pedagogice, takie jak: miejsce, czas, nuda, śmiech, bezpieczeństwo, prywatność. Obrazy otwierają przed badaczem nowe wymiary, niedostępne przy użyciu danych tekstowych i werbalnych, gdyż złożoności rzeczywistości edukacyjnej nie da się wyrazić tylko za pomocą słów; zmysł wzroku jest w naszej kulturze jednym z najbardziej odpowiedzialnych za obraz świata, jaki wytwarzamy.

Możliwości wykorzystywania materiałów wizualnych w badaniach pedagogicznych wskazuje także Kamila Zdanowicz-Kucharczyk [2010: 130], która twierdzi, że dzięki analizie danych wizualnych (fotografii) można zrekonstruować świat badanego, zrozumieć znaczenia, jakie nadaje on światu i swojemu w nim życiu. Etnografia wizualna może zatem służyć badaniu edukacyjnych kontekstów procesów zinstytucjonalizowanego kształcenia, utworzonych ze zjawisk rozproszonych i amorficznych, składających się na kulturę wizualną szkoły. Rekonstruowanie jej znaczeń jest szansą

1 Metafora użyta w śródtytule za: [Pink 2008; Nowotniak 2012]. 
na odkrycie złożonych mechanizmów tworzenia i funkcjonowania reguł społecznych i kulturowych, określających jej odmienność. Dzięki swojemu potencjałowi, badania wizualne pozwalają na uchwycenie tego, co jest „widoczne, lecz niedostrzegalne" [Nowotniak 2012: 259]. Dane wizualne są dla pedagogiki szansą otwarcia się na kategorie graniczne, wzbogacające myślenie pedagogiczne i demistyfikujące jej ograniczenia [Nowotniak 2012: 62]. Umożliwiają ukazanie niedookreślonych kategorialnie kontekstów wieloznaczeniowej edukacyjnej codzienności.

\section{Bibliografia}

Anker S., Nelkin D. (2003), The molecular gaze. Art in the genetic age, Cold Spring Harbor Banks M. (2009), Materiały wizualne w badaniach jakościowych, Niezbędnik Badacza, Warszawa

Banks M., Ruby J. (2011), Made to be seen: Perspectives on the history of visual anthropo$\log y$, Chicago

Barone T. (2001), Science, art, and predispositions of educational researchers, „Educational Researcher", Oct.

Becker H.S. (1995), Visual sociology, documentary photography, and photojournalism: It's (almost) all a matter of context, „Visual Sociology”, nr 10

Belting H. (2007), Antropologia obrazu. Szkice do nauki o obrazie, Kraków

Broeckmann A. (2015), Trudny dialog między „sztuka” a „nauka”, (w:) Materiały z konferencji Co sztuka może dać nauce?, Wrocław, 14.05.2015, http://wro2015.wrocenter. $\mathrm{pl} /$ site/pl/conferences/conference-what-can-art-do-for-science/ [24.08.2015]

Cole A.L., Knowles J.G. (2007), Arts-informed research, (w:) J.G. Knowles, A.L. Cole (red.), Handbook of the arts in qualitative research, Thousand Oaks - London New Delhi

Bylica U., Dąbrowski B. (2009), Rola kabaretów młodzieżowych w rozwijaniu kompetencji uczniów w zakresie krytycznego myślenia, „Pedagogika Kultury”, t. 5

Collier J. Jr., Collier M. (1999), Visual anthropology: Photography as a research method, Albuquerque

Dikovitskaya M. (2005), Visual culture. The study of the visual after the cultural turn, Cambridge

Drozdowski R., Krajewski M. (2010), Za fotografię! W stronę radykalnego programu socjologii wizualnej, Warszawa

Ferenc T. (2001), Socjologia obrazu, socjologia fotografii - praktyki badawcze, „Przegląd Socjologiczny", nr 2

Ferenc T. (2005), Sztuka fotografowania biedy - komu służa zdjęcia nędzy?, „Kultura i Społeczeństwo", nr 4 
Finley S. (2005), Arts-based inquiry. Performing revolutionary pedagogy, (w:) N.K. Denzin, Y.S. Lincoln (red.), The Sage handbook of qualitative research, Thousand Oaks - London - New Delhi

Frąckowiak M., Rogowski Ł. (2009), W poszukiwaniu polskiej socjologii wizualnej, „Kultura i Społeczeństwo", nr 1

Hejnicka-Bezwińska T. (2008), Pedagogika ogólna, Warszawa

Huss E., Cwikel J. (2005), Reserching creations. Applying arts-based research to Bedouin women's drawings, „International Journal of Qualitative Methods”, t. 4, nr 4

Kamiński S. (1992), Nauka i metoda. Pojęcie nauki i klasyfikacja nauk, Lublin

Kawecki I. (2009), Dane wizualne w badaniach pedagogicznych, „Pedagogika Kultury” 2009 , t. 5

Kisseleva O. (2015), Artysta jako badacz: nowe procesy i materiały w sztuce współczesnej (w:) Materiały z konferencji Co sztuka może dać nauce?, Wrocław, 14.05.2015, http:// wro2015.wrocenter.pl/site/pl/conferences/conference-what-can-art-do-for-science/ [24.08.2015]

Kluszczyński R.W. (2011), Art@science. O związkach między sztuka i nauką, (w:) R.W. Kluszczyński (red.), W stronę trzeciej kultury. Koegzystencja sztuki, nauki i technologii, Gdańsk, CSW, http://www.academia.edu/4485206/art_at_science._O_zwiazkach_miedzy_sztuka_i_nauka [02.09.2014]

Konecki K.T. (2005a), Ludzie $i$ ich zwierzęta. Interakcjonistyczno-symboliczna analiza świata społecznego zwierząt domowych, Warszawa

Konecki K.T. (2005b), Wizualne wyobrażenia. Główne strategie badawcze w socjologii wizualnej a metodologia teorii ugruntowanej, „Przegląd Socjologii Jakościowej” 2005, t. 1, nr 1, http://www.qualitativesociologyreview.org/PL/Volume1/PSJ_1_1_Konecki.pdf [17.02.2014]

Konecki K.T. (2008), Wizualna teoria ugruntowana. Rodziny kodowania wykorzystywane $w$ analizie wizualnej, „Przegląd Socjologii Jakościowej”, t. 4, nr 3 http://www.qualitativesociologyreview.org/PL/Volume8/PSJ_4_3_Konecki.pdf [01.05.2014]

Konecki K.T. (2010), Wizualna Teoria Ugruntowana. Nauczanie teorii ugruntowanej przy pomocy obrazów i analizy wizualnej, „Przegląd Socjologii Jakościowej”, t. 6, nr 2, http://www.qualitativesociologyreview.org/PL/Volume13/PSJ_6_2_Konecki.pdf [17.02.2014]

Konecki K.T. (2012), Wizualna teoria ugruntowana. Podstawowe zasady i procedury, „Przegląd Socjologii Jakościowej”, t. 8, nr 1, http://www.qualitativesociologyreview.org/PL/Volume18/PSJ_8_1_Konecki.pdf [21.05.2014]

Koseła K. (1990), Interpretacja fotografii. Krok ku socjologii wizualnej, „Kultura i Społeczeństwo", nr 1

Krzychała S., Zamorska B. (2008), Dokumentarna ewaluacja szkolnej codzienności, Wrocław

Kubinowski D. (2011), Jakościowe badania pedagogiczne. Filozofia, metodyka, ewaluacja, Lublin

Kubinowski D. (2013), Rozwój badań jakościowych w pedagogice polskiej na przełomie XX i XXI wieku. Idiomatyczność. Synergia. Emergencja, Lublin

Levin D. M. (red.) (1993), Modernity and the hegemony of vision, Berkeley 
Magala S. (1978), Fotografia jako element teatralizacji życia społecznego, „Fotografia”, nr 4 Magala S. (2012), Antropologia wizualna, (w:) D. Jemielniak (red.), Badania jakościowe. Podejścia i teorie, t. 1, Warszawa

Mendel M. (red.) (2006), Pedagogika miejsca, Wrocław

Mendel M., Ejsmont M., Kosmalska B. (red.) (2009), Obraz. Przestrzeń, popkultura. Inspiracje badawcze w polu pedagogiki społecznej, Toruń

Mitchell W.J.T. (1994), Picture theory. Essays on verbal and visual representation, Chicago Mitchell W.J.T. (2009), Zwrot piktorialny, „Kultura Popularna”, nr 1

Nalaskowski A. (2002), Przestrzenie i miejsca szkoły, Kraków

Niziołek K. (2010), Między amatorstwem a etnografią. Fotografia jako narzędzie edukacji (w:) A. Młynarczuk, M. Sokołowski (red.), Uwiecznić Atlantydę. Wielokulturowość Podlasia w edukacji nieformalnej, Białystok, http://fundacja.uwb.edu.pl/images/a galeria_fundacja/publikacje/ [05.10.2014]

Niziołek K. (2011), Fotografia uczestnicząca. Od jakościowych badań światów społecznych do interwencji socjologicznej, „Qualitative Sociology Review”, t. 7, nr 1, http://www. qualitativesociologyreview.org/PL/Volume15/PSJ_7_1_Niziolek.pdf [11.09.2014]

Niziołek K. (2012), Miejskie „laboratorium” wielokulturowości. Socjologiczno-fotograficzna próba obserwacji relacji międzykulturowych $w$ przestrzeni publicznej Białegostoku, „Pogranicze. Studia Społeczne”, t. 20

Nowotniak J. (2001a), Szkoła czyli świat w obrazku, „Nowa Szkoła”, nr 8

Nowotniak J. (2001b), Szkoła w obiektywie uczniów. Fotografia jako narzędzie opisu, (w:) B. Niemierko, M.K. Szmigiel (red.), Teoria i praktyka oceniania zewnętrznego, Kraków

Nowotniak J. (2012), Etnografia wizualna w badaniach i praktyce pedagogicznej, Kraków

Nowotniak J. (2013), Badania etnograficzne z elementami wizualnymi w kształceniu akademickim - możliwości i ograniczenia, „Opuscula Sociologica”, nr 4

Olechnicki K. (2003a), Antropologia obrazu. Fotografia jako metoda, przedmiot i medium nauk społecznych, Warszawa

Olechnicki K. (red.) (2003b), Obrazy w działaniu. Studia z socjologii i antropologii obrazu, Toruń

Pink S. (2008), Etnografia wizualna. Obrazy, media i przedstawienie w badaniach, Kraków

Piejko M. (2008), Skarby pamięci. Socjologiczna analiza fotografii rodzinnej, „Przegląd Socjologii Jakościowej” 2008, t. 4, nr 3, http://www.qualitativesociologyreview. org/PL/Volume8/PSJ_4_3_Piejko.pdf [10.09.2014]

Popper K.R. (2002), Wiedza obiektywna. Ewolucyjna teoria epistemologiczna, Warszawa

Pryszmont-Ciesielska M. (2011), Starość w obiektywie, (w:) M. Malec (red.), Edukacyjne, kulturowe i społeczne konteksty starości, Wrocław

Reichle I. [2015] Sztuka, nauka i społeczeństwo: kiedy sztuka staje się zinstytucjonalizowanq praktyka społeczna (w:) Materiały z konferencji Co sztuka może dać nauce?, Wrocław, 14.05.2015, http://wro2015.wrocenter.pl/site/pl/conferences/conference -what-can-art-do-for-science/ [24.08.2015]

Ripa (2010), Ikonologia, Kraków

Rose G. (2010), Interpretacja materiałów wizualnych. Krytyczna metodologia badań nad wizualnością, Warszawa 
Rubacha K. (2004), Edukacja jako przedmiot pedagogiki i jej subdyscyplin, (w:) Z. Kwieciński, B. Śliwerski (red.), Pedagogika, t.1, Warszawa

Rutkowiak J. (1994), Wielość języków pedagogiki a problem jej tożsamości, (w:) H. Kwiatkowska (red.), Ewolucja tożsamości pedagogiki, Warszawa

Schnettler B. (2008), W stronę socjologii wiedzy wizualnej, „Przegląd Socjologii Jakościowej”, t. 4, nr 3, http://www.qualitativesociologyreview.org/PL/Volume8/PSI_4_3_ Schnettler.pdf [10.09.2014]

Siarkiewicz E. (2007), W poszukiwaniu skuteczności poradnictwa. Analiza dwóch narracji utrwalonych $w$ fotografii, „Teraźniejszość - Człowiek - Edukacja”, nr 2

Sikora S. (2003), Antropologia wizualna i film etnograficzny, Warszawa

Sikora S. (2004), Fotografia między dokumentem a symbolem, Izabelin

Sławecki B. (2012), Znaczenie paradygmatów w badaniach jakościowych, (w:) D. Jemielniak (red.), Badania jakościowe. Podejścia i teorie, t. 1, Warszawa

Sztejnberg A. (2006), Komunikacyjne środowisko nauczania i uczenia się, Warszawa

Sztejnberg A., Jasiński T. (2007), Proksemika w komunikacji społecznej, Płock

Sztompka P. (2005), Socjologia wizualna. Fotografia jako metoda badawcza, Warszawa

Tatarkiewicz W. (1982), Dzieje sześciu pojęć, Warszawa

Taylor P.G., Wilder S.O., Helms K.R. (2007), Walking with a ghost. Arts-based research, music videos, and the re-performing body, „International Journal of Education \& the Arts", t. 8, nr 7, www.ijea.org/v8n7/index.html [28.08.2015]

Whitehead A.N. (1998), Nauka i świat współczesny, Warszawa

Worth S. (1981), Studying Visual Communication, Philadelphia

Zdanowicz-Kucharczyk K. (2010), Fotografia oknem badacza na świat, (w:) H. Kędzierska (red.), Jakościowe inspiracje $w$ badaniach edukacyjnych, Olsztyn 
SUMMARY

\section{Between art and scientific research. Visual ethnography as a source of knowledge about the educational reality}

The starting point of this article is the relationship of art and science from the perspective of epistemological and ontological insights of philosophers of science and researchers of contemporary art. Further on, the author presents the specificity of the interaction of art and pedagogy, in which the complex subject of the latter opens the field to various sources, styles and languages of knowing and understanding of the world and the human being (including the language of the arts). Seeing art as an important exploration tool for the analysis of education in qualitative pedagogical research, the author summarizes the assumptions of visual ethnography - a research method that, as she explains, oscillates between art and science (with its methodological appeal to the image as the primary medium of the art). In the conclusion, she indicates cognitive and practical benefits which may result from using the concepts that derive from the arts as a source of knowledge about the educational reality.

Keywords:

art, education, methodology, qualitative research, visual ethnography 